\title{
Does Power Corrupt? The Evidence from Event-Related Potentials
}

\author{
Yaozhong Liu, Junjie Huang \\ School of Management, Jinan University, Guangzhou, China \\ Email: jun-wong@hotmail.com
}

Received 30 December 2014; accepted 18 January 2015; published 23 January 2015

Copyright (C) 2015 by authors and Scientific Research Publishing Inc.

This work is licensed under the Creative Commons Attribution International License (CC BY). http://creativecommons.org/licenses/by/4.0/

(c) (i) Open Access

\section{Abstract}

The approach/inhibition theory of power suggested that power conduced to more reward-related behavior, while powerless individual had more inhibited behavior. In this study, participants were told to take part in the dictator game and the ultimatum game, which respectively made them feel powerful or powerless. In the meanwhile, ERPs (Event-Related Potentials) was also adopted in the experiment. After comparing the behavioral and potential differences between those two power conditions, the study found that people felt more powerful and allocated less interests to the counterparts when they played the dictator game than that in the ultimatum game. Four types of ERP component were found in this study: P2, N2, P3 and LNC. In the power condition, participants probed larger N2 than in the powerlessness condition. Particularly, the P2 of left cerebral hemisphere was larger than that on the right. However, N2, P3 and LNC probed in powerlessness condition were larger. The results implied that powerful individual put more cognitive resource at the early stage of decision-making while powerless individual allocated more cognitive recourse in the later stage. Besides, more conflict processing might be performed when people had less power. The study found a new neural evident to support the approach/inhibition theory of power.

\section{Keywords}

Power, Dictator Game, Ultimatum Game, P2, N2, P3, LNC

\section{Introduction}

The society we live is complex while many decisions should be made in the situation of social interaction [1]. Social decision-making would not only affect the decision maker themselves, but also have an effect on others [2]. A study has pointed out that the conflict between self-interests and others' interests is the most critical to social decision-making [3]. Studies have also found that status [4], information symmetry [5] and sense of con- 
trol [6] could affect the balance between self-interests and the interests of others, which seems that power plays an important role in social decision-making, as power is close related to status, information symmetry and sense of control.

Power is defined as the ability to control resources, own and others', without social interference [7]. Some researches focused on how power affect individual's behavior, which suggested that power can lead to corrupt [8]. Because power could make people pay more attention to their own interests while put the interests of others' aside [9].

The approach/inhibition theory of power is one of the most representative theory in terms of power effect [10]. The theory explains the approach/inhibition effect of power on individual's emotion, attention, social cognition and behavior. The theory suggests that sense of power is related to individual's behavior approach system (BAS), which can enhance the positive emotion expression and pay more attention to reward and self-goal achieving through the neural path of catechin polyphenols amine and dopamine [11]. BAS is also associated to individual's disinhibited social behavior. However powerlessness is related to individual's behavior inhibition system (BIS), which would enhance the expression of negative emotion, leading to more concerned about information of punishment and threat. A study has found that BIS consist of the hippocampal system [12]. Contract to BAS, BIS is associated to individual's inhibited social behavior. Maarten (2012) measured EEG (Electroencephalograph) activity while participants engaged in a task priming either high or low social power, which turned out that high social power is indeed associated with greater left-frontal brain activity compared to low social power, providing the first neural evidence for the theory that high power is associated with approach-related motivation [13]. However, results fail to further illustrate how power affect individual's social behavior.

Studies have shown that brain potential component like P2, N2, P3 and LNC could reflect the power effect. P2 is a positive deflection at approximately 150 - $250 \mathrm{~ms}$ [14]. Researches have proved that some advanced cognitive process elicited enlarged frontal, parietal, and occipital P2 [15]. Some scholars found that larger P2 would be elicited in common interests condition than in conflicting interests conditions [16], showing that conflicting interests elicit more inhibition and conflict resolving process, while common interests are more motivationally significant to human [17]. N2 is a negative deflection after P2, studies show that N2 is the index of conflicting as N2 is elicited when occur target conflict and reaction conflict [15]. P3 is a positive deflection at approximately $300 \mathrm{~ms}$, which is closely related to advanced cognitive process. And some advance cognitive process elicited enlarge temporal, parietal and occipital P3 [18]. Research of inhibition process shows that target conflict elicited enlarge LNC (late negative component) [19]. Then LNC can also be the index of measuring individual's mental conflict in conflicting interests situation.

In order to find the neural evidences for the approach/inhibition theory of power, this study observed participants' social decision-making in different power conditions which are manipulated by dictator game (DG, power condition) and ultimatum game (UG, powerlessness condition). As in the dictator game, subjects can distribute the money without any limitation, so they are supposed to be more powerful in this task. However, in the ultimatum game, the subjects had to distribute the money with consideration, as the responder may reject the distribution if he/she thought it was not fair, and then both of them may get 0 [20]. Therefore, subjects in this task should feel less powerful. Subjects' EEG was also be detected while they were making decision in DG and UG. This study not only discussed how power affects individuals' social decision-making and its neural activities process, but also helped predict the action trend of powerful individual and powerless individual in organizations, which makes this study have both theoretical and practical significance. Based on the researches and studies mentioned above, this study supposed that power will activated individuals' BAS, leading to more self-interest oriented behavior and allocating more cognitive resource to reward information, while powerlessness activated one's BIS, leading to inhibited social behavior, paying more cognitive resource to deal with the conflict between self-interests and others' interests.

\section{Methods}

\subsection{Participants}

Fifteen healthy students (8 males and 7 females) participated in this study. The participants were aged 20 to 25 years. All of the participants were right-handed, and none of them were reported to have any mental health and vision problems. All of the participants got monetary reward after the experiment. 


\subsection{Materials and Procedure}

All of the participants were asked to complete DG and UG, to manipulate participants' sense of power. Especially, DG referred to the power condition, while UG was the powerlessness condition. The main dependent variables were the amount of money they divided to others and the reaction tome in DG and UG. The EEG while they made the decision was also detected in this study. Participants sat in a comfortable position in an armchair in front of a computer screen. All stimulus was presented by E-prime2.0. All participants had to finish 4 blocks of games (2 were DG and 2 were UG). Each block had 60 trails and presented in accordance with ABBA sequence. Participants were asked to fill up a questionnaire to record their sense of entitlement as soon as they finished one block of the experiment.

\subsubsection{Dictator Game and Ultimatum Game}

Participants were told to complete a money dividing task with another student (in fact there was only one subject in one experiment, the other subject was the assistant for this study), and their reward depend on how much money they get in the experiment. In DG, every trail began with a “+” as an fixation for 500 ms; then a number $(55,65,75,85,95)$ was presented in the screen, which was the total amount of interests. What the participants needed to do was to decide how much he/she wanted to divided to his/her counterpart by inputting a certain number (see Figure 1). The task of UG was nearly the same. However, the subject was told that in UG, if the counterpart (respondent) rejected the project, he/she would get 0 in the trail.

\subsubsection{Scale of Self-Reported Entitlement}

The measure of perceptions of the relative power was collected as soon as they finished one block of the experiment. Participants were asked to rate on a scale from 0 to 100, "What is your power in this task?" On the scale, 0 was labeled "my counterpart has all the power;” 50 was labeled “equal power;” and 100 was labeled "I have all the power.” [21].

\subsection{ERP Recording and Pre-Processing}

The EEG was recorded continuously with electrodes mounted on an elastic cap from 64 standard locations according to the 10 - 20 electrode system. Two electrodes were placed on the right and left mastoids. An electrode placed in front of Fz served as the ground. Eye movements were monitored by deriving bipolar recordings from electrodes placed to the right eye (HEOG); blinks were monitored by deriving bipolar recordings from electrodes placed to the left eye (VEOG). The EEG and EOG signals were amplified with a low-pass filter $200 \mathrm{~Hz}$ by Brain Products amplifier and digitized at a sampling rate of $1000 \mathrm{~Hz}$.

Data were re-referenced to the average of the two mastoids and re-filtered digitally with a low-pass of $40 \mathrm{~Hz}$. Target-related epochs started 200 ms before and ended 1000 ms after stimulus presentation. All amplitude values were referred to the $200 \mathrm{~ms}$ pre-cue baseline. Trials were automatically eliminated if the voltage exceeded $\pm 50 \mu \mathrm{V}$ at either the vertical or horizontal EOG channels, or if it exceeded $\pm 70 \mu \mathrm{V}$ at any other channel. Separate averages were computed for each type of target based on the task (DG or UG). Topographical analysis and the previous literature were used to determine the time windows and electrodes for analysis.

Target P2 was analyzed between 200 and 240 ms post-stimulus at F3/4, Fz, C3/4, Cz, P3/4, Pz. Target N2 was analyzed between 250 and 290 ms post stimulus at F3/4, Fz, C3/4, Cz, P3/4. Target P3 followed a centroparietal distribution and was analyzed between 300 and $500 \mathrm{~ms}$ at Cz. Target LNC followed a frontal distribution and was analyzed between 700 and $900 \mathrm{~ms}$ at F3/4, Fz (see Figure 2). The averaged amplitudes of the ERP components were subjected to ANOVA. A repeated-measures ANOVA was performed to look at the effect of the late-

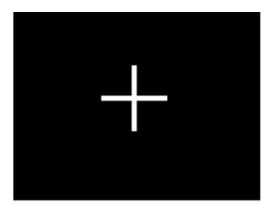

$500 \mathrm{~ms}$

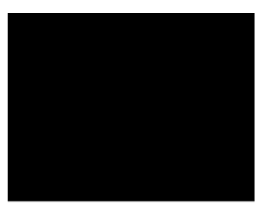

$500 \sim 800 \mathrm{~ms}$

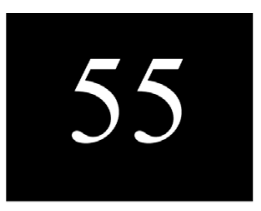

$2000 \mathrm{~ms}$

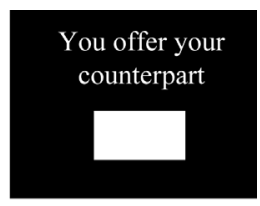

$3000 \mathrm{~ms}$

Figure 1. The procedure of DG and UG. 


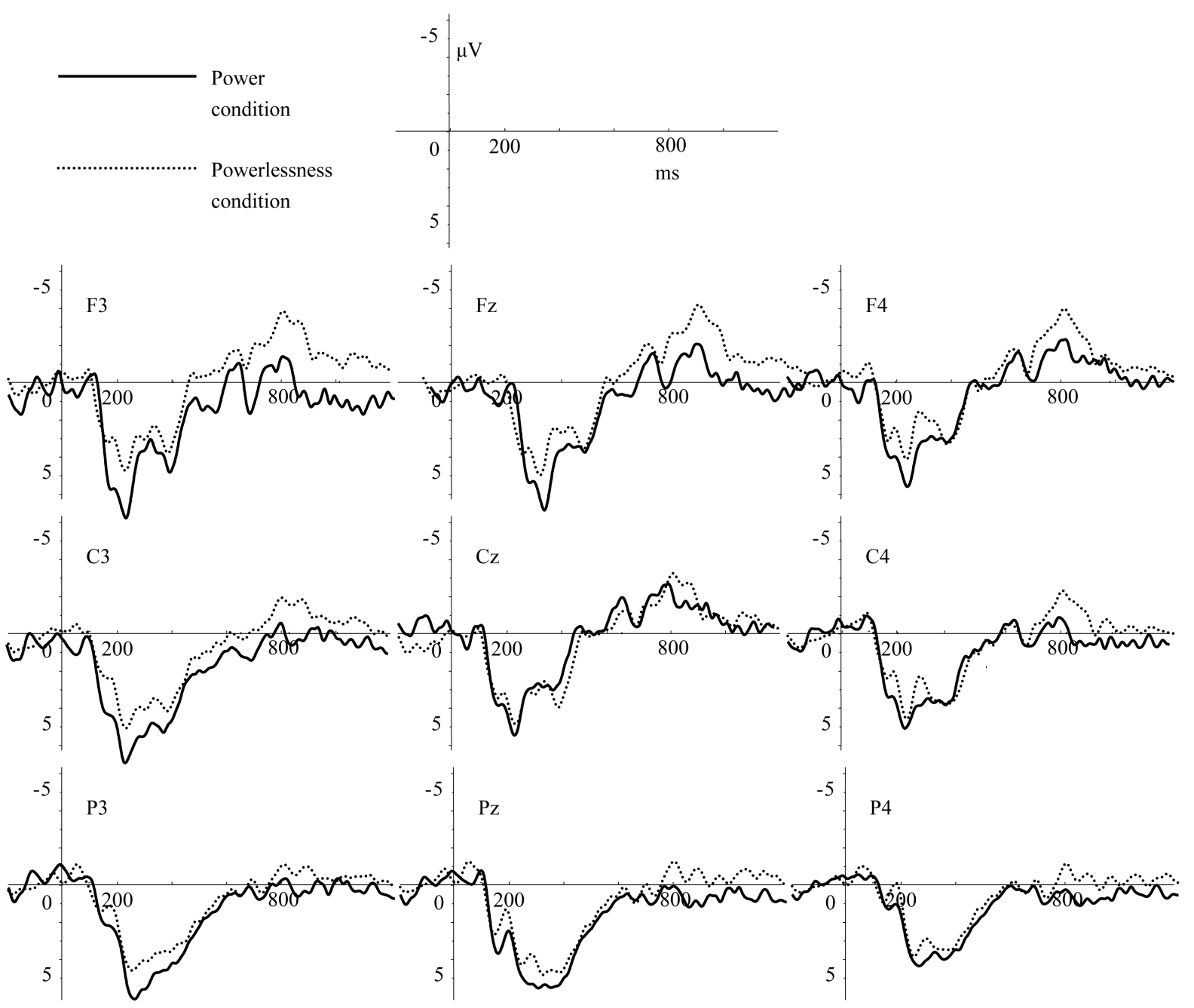

Figure 2. ERPs from -200 to $1000 \mathrm{~ms}$ to the target stumili in the four tasks blocks from the individual elctrodes.

ralization (left-F3, C3, P3, right-F4, C4, P4) and topography (frontal-F3/F4, central-C3/C4, parietalP3/P4) for different ERPs' components in both groups. Greenhouse-Geisser corrections are reported. The differences within and between factors/groups were considered statistically significant at $\mathrm{p}<0.05$. The significant main effects and interactions were further analyzed with post-hoc Tukey multiple-range tests (alpha 0.05).

\section{Results}

\subsection{Behavioral Results}

The score of participants' report in scale of self-reported entitlement after each task were subjected to the single factor repeated ANOVA, in order to check whether different types of task (DG and UG) could manipulate the entitlement of participants. The result showed that participants in DG felt much power $(\mathrm{M}=78.93 \pm 17.58)$ than in UG $(\mathrm{M}=40.33 \pm 13.18), F(1,14)=42.61, p<0.001, \eta^{2}=0.68$.

The proportion of the interest participants to their counterparts (quantum) and the reaction time (RT) of different types of task were also subjected to the single repeated ANOVA. Results showed that participants in power condition divided less interests to their counterparts $[\mathrm{M}=(37.50 \pm 11.02) \%]$ than those in powerlessness condition $[(\mathrm{M}=56.99 \pm 9.26) \%]$, and this difference was significant, $F(1,14)=29.23, p<0.001, \eta^{2}=0.75$. Besides, RTs in power condition $(\mathrm{M}=1034.45 \pm 324.75)$ was shorter than those in powerlessness condition $(\mathrm{M}=$ $1348.42 \pm 306.91), F(1,14)=43.99, p<0.001, \eta^{2}=0.76$. 


\subsection{ERP Results}

\subsubsection{P2}

The amplitudes of P2 were subjected to a 2(condition: power/powerlessness) $\times$ 3(lateralization: F3/C3/P3, Fz/ $\mathrm{Cz} / \mathrm{Pz}, \mathrm{F} 4 / \mathrm{C} 4 / \mathrm{P} 4) \times 3$ (topography: F3/Fz/F4, C3/Cz/C4, P3/P4/P4) repeated ANOVA analysis. Results showed a significant main effect of power condition, $F(1,14)=5.36, p=0.04, \eta^{2}=0.27$. Power condition elicited larger P2 than those in powerlessness condition. Besides, the main effect of lateralization was also significant, as the $\mathrm{P} 2$ of the left were significantly larger than those elicited from the center and right, $F(2,28)=7.72, p=0.01, \eta^{2}=$ 0.36 . The results of interaction effect showed that an interaction of power condition and lateralization, $F(2,28)=$ 4.87, $p=0.04, \eta^{2}=0.26$. The following simple effect analysis showed that in powerlessness condition, no significant difference of $\mathrm{P} 2$ was found, $F(2,13)=2.89, p=0.09, \eta^{2}=0.31$. However in power condition, $\mathrm{P} 2$ of the left $(\mathrm{M}=7.09 \pm 1.02 \mu \mathrm{V})$, center $(\mathrm{M}=6.01 \pm 0.80 \mu \mathrm{V})$ and the right $(\mathrm{M}=4.53 \pm 0.60 \mu \mathrm{V})$ were significantly different, $F(2,13)=5.92, p=0.02, \eta^{2}=0.48$. The simple effect analysis also showed that the P2 of the left was significantly different between power condition and powerlessness condition, $F(1,14)=8.14, p=0.01, \eta^{2}=$ 0.29 , suggesting that in power condition, the left brain region elicited larger $\mathrm{P} 2$ than those in powerlessness condition. However, the effect of condition was not significant in neither the center $\left(F(1,14)=3.27, p=0.09\right.$, $\eta^{2}=$ $0.19)$ nor the right $\left(F(1,14)=2.93, p=0.11, \eta^{2}=0.17\right)$.

\subsubsection{N2}

The amplitudes of P2 were subjected to a 2(condition: power/powerlessness) $\times$ 3(lateralization: F3/C3/P3, Fz/ $\mathrm{Cz} / \mathrm{Pz}, \mathrm{F} 4 / \mathrm{C} 4 / \mathrm{P} 4) \times 3($ topography: F3/Fz/F4, C3/Cz/C4, P3/P4/P4) repeated ANOVA analysis. Results showed a main effect of condition, $F(1,14)=17.21, p=0.001, \eta^{2}=0.55$. Larger N2 was elicited in powerlessness condition than that in power condition. A main effect of lateralization was also found, showing that the N2 elicited in the center was significantly larger than those in the left and the right. $F=(2,28)=6.50, p=0.005, \eta^{2}=0.317$.

\subsubsection{P3}

The P3 at Cz was subjected to ANOVA, and the results showed a main effect of condition, $F=(1,14)=4.89, p=$ $0.04, \eta^{2}=0.259$. Powerlessness condition elicited larger $\mathrm{P} 3$ at $\mathrm{Cz}(\mathrm{M}=4.67 \pm 3.15 \mu \mathrm{V})$ than power condition $(\mathrm{M}=5.59 \pm 3.78 \mu \mathrm{V})$.

\subsubsection{LNC}

The amplitudes of LNC were subjected to a 2(condition: power/powerlessness) $\times 3$ (lateralization: F3/Fz/F4) repeated ANOVA analysis. The results showed that the main effect of condition was significant, $F=(1,14)=$ 4.39, $p=0.05, \eta^{2}=0.239$. Powerlessness condition elicited larger LNC than power condition. While the main effect of lateralization $\left(F=(1,14)=0.86, p=0.43, \eta^{2}=0.06\right)$ nor the interaction effect $(F=(1,14)=0.47, p=$ $\left.0.61, \eta^{2}=0.03\right)$ were not found.

\section{Discussion}

This study proved that power influence how individual balance self-interests and the others' in social-decision making, using DG and UG to manipulate participants sense of entitlement. And results showed that participants feel more powerful in DG as they could divide the interests without any limitation. However, participants in UG felt less powerful as their interests division was decided by their counterparts and themselves. The results of quantum and RT supported the approach/inhibition theory of power. On one hand, the theory suggested that power individual performs more approach behavior like self-goal achieving as power activate BAS. While individual with less power performs more inhibition behavior as powerlessness activates BIS [10]. In this study, participants divided less interests to his/her counterpart when he/she had more power, but dividing more interests to his/her counterparts when he/she was powerless. On the other hand, RT in power condition was shorter than that in powerlessness condition, which is consistent with the theory which suggested that individual with less power pay too more attention about other information (like limitation and punishment) to make a quick decision [22]. Besides, previous researches also suggested that power individual tends to perform social-decision making with intuition, leading to more self-interested behavior, however, powerless individuals focus on other factors not only self-interest in social decision-making, leading to behaving equally instead [8].

The ERP results showed that power affects individuals' cognitive resource allocation in social decision-mak- 
ing, especially, power individuals allocate more cognitive resource in the early stage of social decision-making while powerless individuals pay more cognitive resource in the later stage of social decision making. Previous researches have proved that P2 is related to one's advanced cognitive processing [14]. A study also suggested that P2 reflects the integrated processing of motivational information and cognitive information [23]. In this study, larger P2 was elicited in power condition than in powerlessness condition, implying that in power condition, individuals tend to allocate more cognitive resource at the early stage of social decision-making than in powerlessness condition. As power activates individuals’ BAS, which made them tend to pay more attention to the information about reward and self-goal. And the larger P2 in power condition than in powerlessness condition may also prove this situation. Besides, as the results showed that in power condition, the P2 of left cerebral hemisphere is larger than that on the right and the center, this study also found the evidence to support the hypothesis that BAS is in the left brain region [13]. Then it would be obvious that power individuals allocate more cognitive to the reward information as their BAS is activated, leading to more attention to the target in this study and larger P2 was elicited in power condition.

However, the larger P3 elicited in powerlessness condition implying that participants in powerless condition allocated more cognitive resource in the later stage of social decision-making compared with power condition, As P3 is related to advanced cognitive processing and can measure the effectiveness of information process [18], P3 can reflect the situation of cognitive resource consuming in social decision-making. According to the approach/inhibition theory of power, BIS would be activated when individuals feel powerless, leading them focus on the information about limitation and punishment, making them behave less self-interest. It may because powerless individuals pay more attention to equal or others approve instead of reward or self-goal. And making an equal decision needs more cognitive resource in the late stage of social decision-making, turning out that lager P3 was elicited in powerlessness condition in this study. In a word, power can affect individuals' allocation of cognitive resource, depending of BAS or BIS is activated.

The ERPs results also showed that the motivational conflict happened to participants in powerlessness condition, as a larger N2 was found in powerlessness condition. According to previous study, N2 is an index of mental conflict [24]. Therefore, a larger N2 should be elicited if individual feel more conflicts to the decision. Particularly, as powerlessness condition activated participants BIS, leading them pay more attention to the information about punishment, loss, and interpersonal relationship, it is easy to understand that powerless participants should feel the conflict between the motive of getting more self-interests and the motive of getting approve from the counterparts. While participants in power condition would not have this conflict as they have the power to control both self-interests and the interests of his/her counterparts.

Another evidence that participants in powerlessness condition have more motivational conflict is that larger LNC is elicited in powerlessness condition. LNC is a late negative component, which is usually elicited while the participants are "making a decision". Previous study also suggested that LNC plays an important role in dealing with mental conflict [19]. As powerlessness activates individuals’ BIS, making them become more restrictive by other information like punishment rather than reward, while individuals with power can focus on the information of reward and self-goal as power activates their BAS. In this study, the larger LNC in powerlessness condition than in power condition may infer that powerless participants felt the pressure from the sense of fairness and their conscience. The conflict between self-interests and others' interests led to larger LNC in this study.

There are an increasing number of researches suggesting that power can not only make people “corrupt”, but also make them “enable”. As power also help people think more comprehensively and strength the interpersonal sensitivity [25] [26]. Katherine et al. (2012) also found the mediation effect of moral identity in the effect of power to self-interest behavior [27]. Some scholars have started to apply fMRI to research of power effect. In further studying, other factors should be considered to make a clear knowledge of how power effect self-interested behavior and its neuromechanism.

\section{Conclusion}

Power has the approach/inhibition to individuals' social decision-making. In power condition, individuals allocate more cognitive resource to the reward and self-goal, leading to more self-interested behavior in social decision-making. While in powerlessness condition, individuals allocate more cognitive resource to interpersonal relationship and punishment. They feel more conflicts between self-interested pursuing and interpersonal factors, 
making them behave more equally in social decision-making.

\section{References}

[1] Rilling, J.K. and Sanfey, A.G. (2011) The Neuroscience of Social Decision-Making. Annual Review of Psychology, 62, 23-48. http://dx.doi.org/10.1146/annurev.psych.121208.131647

[2] Fehr, E. andCamerer, C.F. (2007) Social Neuroeconomics: The Neural Circuitry of Social Preferences. Trends in Cognitive Sciences, 11, 419-427. http://dx.doi.org/10.1016/j.tics.2007.09.002

[3] Su, Y.J., Zhang, H. and Zhang, K. (2012) Social Decision-Making: The Equilibrium between Self-Interest and the Interests of Others. Journal of Psychological Science, 35, 1423-1428.

[4] Piff, P.K., Stancato, D.M., Côté, S., Denton, R.M. and Keltner, D. (2012) Higher Social Class Predicts Increased Unethical Behavior. Psychological and Cognitive Sciences, 109, 4086-4091.

[5] Vuolevi, J.H.K. and Van Lange, P.A.M. (2010) Beyond the Information Given: The Power of a Belief in Self-Interest. European Journal of Social Psychology, 40, 26-34.

[6] Moore, D.A. and Loewenstein, G. (2004) Self-Interest, Automaticity, and the Psychology of Conflict of Interest. Social Justice Research, 17, 189-202. http://dx.doi.org/10.1023/B:SORE.0000027409.88372.b4

[7] Galinsky, A.D., Gruenfeld, D.H. and Magee, J.C. (2003) From Power to Action. Journal of Personality and Social Psychology, 85, 453-466. http://dx.doi.org/10.1037/0022-3514.85.3.453

[8] Galinsky, A.D., Magee, J.C., Inesi, M.E. and Gruenfeld, D.H. (2006) Power and Perspectives Not Taken. Psychological Science, 17, 1068-1074. http://dx.doi.org/10.1111/j.1467-9280.2006.01824.X

[9] DeCelles, K.A., DeRue, D.S., Margolis, J.D. and Ceranic, T.L. (2012) Does Power Corrupt or Enable? When and Why Power Facilitates Self-Interested Behavior. Journal of Applied Psychology, 97, 681-689. http://dx.doi.org/10.1037/a0026811

[10] Keltner, D., Gruenfeld, D.H. and Anderson, C. (2003) Power, Approach, and Inhibition. Psychological Review, 110, 265-284. http://dx.doi.org/10.1037/a0026811

[11] Stellar, J.R. and Stellar, E. (1985) The Neurobiology of Motivation and Reward. Springe Verlag, New York, 87-92. http://dx.doi.org/10.1007/978-1-4615-8032-4

[12] Gray, J.A. (1990) Brain Systems That Mediate Both Emotion and Cognition. Cognition and Emotion, 4, 269-288. http://dx.doi.org/10.1080/02699939008410799

[13] Boksem, M.A.S., Smolders, R. and De Cremer, D. (2012) Social Power and Approach-Related Neural Activity. Social Cognitive and Affective Neuroscience, 7, 516-520. http://dx.doi.org/10.1093/scan/nsp006

[14] Crowley, K.E. and Colrain, I.M. (2004) A Review of the Evidence for P2 Being an Independent Component Process: Age, Sleep and Modality. Clinical Neurophysiology, 115, 732-744. http://dx.doi.org/10.1016/j.clinph.2003.11.021

[15] Luck, S.J. and Hillyard, S.A. (1994) Electrophysiological Correlates of Feature Analysis during Visual Search. Psychophysiology, 31, 291-308. http://dx.doi.org/10.1111/j.1469-8986.1994.tb02218.x

[16] Boudreau, C., McCubbins, M.D. and Coulson, S. (2009) Knowing When to Trust Others: An ERP Study of Decision Making after Receiving Information from Unknown People. Social, Cognitive, and Affective Neuroscience, 4, $23-34$. http://dx.doi.org/10.1093/scan/nsn034

[17] Wu, Y. and Zhou, X.L. (2012) The Context-Dependency of Fairness Processing: Evidence from ERP Study. Acta Psychologica Sinica, 44, 797-806. http://dx.doi.org/10.3724/SP.J.1041.2012.00797

[18] Hansenne, M. (2000) The P300 Cognitive Event-Related Potential: I. Theoretical and Psychobiologic Perspectives. Clinical Neurophysiology, 30, 191-210. http://dx.doi.org/10.1016/S0987-7053(00)00223-9

[19] Leslie, A.M., Friedman, O. and German, T.P. (2004) Core Mechanisms in “Theory of Mind”. Trends Cognition Science, 8, 528-533. http://dx.doi.org/10.1016/j.tics.2004.10.001

[20] Güth, W., Schmittberger, R. and Schwarze, B. (1982) An Experiment Analysis of Ultimatum Bargaining. Journal of Economic Behavior \& Organization, 3, 367-388. http://dx.doi.org/10.1016/0167-2681(82)90011-7

[21] Wolfe, R.J. and McGinn, K.L. (2005) Perceived Relative Power and Its Influence on Negotiations. Group Decision and Negotiation, 14, 3-20. http://dx.doi.org/10.1007/s10726-005-3873-8

[22] Overbeck, J.R. and Park, B. (2006) Powerful Perceivers, Powerless Objects: Flexibility of Power Holders’ Social Attention. Organizational Behavior and Human Decision Processes, 99, 227-243. http://dx.doi.org/10.1016/j.obhdp.2005.10.003

[23] Potts, G.F. (2004) An ERP Index of Task Relevance Evaluation of Visual Stimuli. Brain \& Cognition, 56, 5-13. http://dx.doi.org/10.1016/j.bandc.2004.03.006 
[24] Ernst, L.H., Ehlis, A., Dresler, T., Tupak, S.V., Weidner, A. and Fallgatter, A.J. (2013) N1 and N2 ERPs Reflect the Regulation of Automatic Approach Tendencies to Positive Stimuli. Neuroscience Research, 75, 239-249. http://dx.doi.org/10.1016/j.neures.2012.12.005

[25] Hall, J.A., Andrzejewski, S.A. and Yopchick, J.E. (2009) Psychological Correlates of Interpersonal Sensitivity: A MetaAnalysis. Journal of Nonverbal Behavior, 33, 149-180. http://dx.doi.org/10.1007/s10919-009-0070-5

[26] Schmid Mast, M., Jonas, K. and Hall, J.A. (2009) Give a Person Power and He or She Will Show Interpersonal Sensitivity: The Phenomenon and Its Why and When. Journal of Personality and Social Psychology, 97, 835-850. http://dx.doi.org/10.1037/a0016234

[27] De Celles, K.A., De Rue, D.S., Margolis, J.D. and Ceranic, T.L. (2012) Does Power Corrupt or Enable? When and Why Power Facilitates Self-Interested Behavior. Journal of Applied Psychology, 97, 681-689.

http://dx.doi.org/10.1037/a0026811 
Scientific Research Publishing (SCIRP) is one of the largest Open Access journal publishers. It is currently publishing more than 200 open access, online, peer-reviewed journals covering a wide range of academic disciplines. SCIRP serves the worldwide academic communities and contributes to the progress and application of science with its publication.

Other selected journals from SCIRP are listed as below. Submit your manuscript to us via either submit@scirp.org or Online Submission Portal.
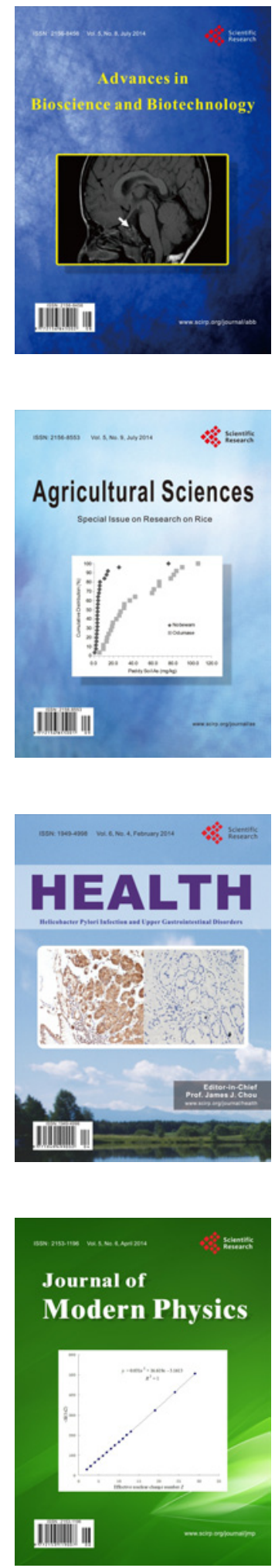
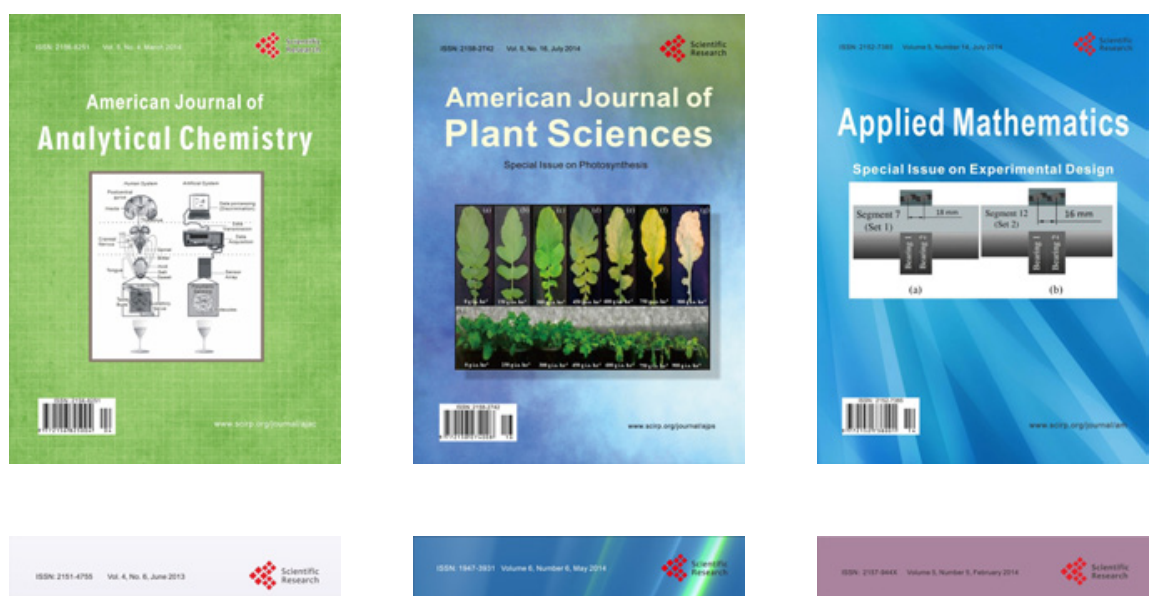

Creative Education
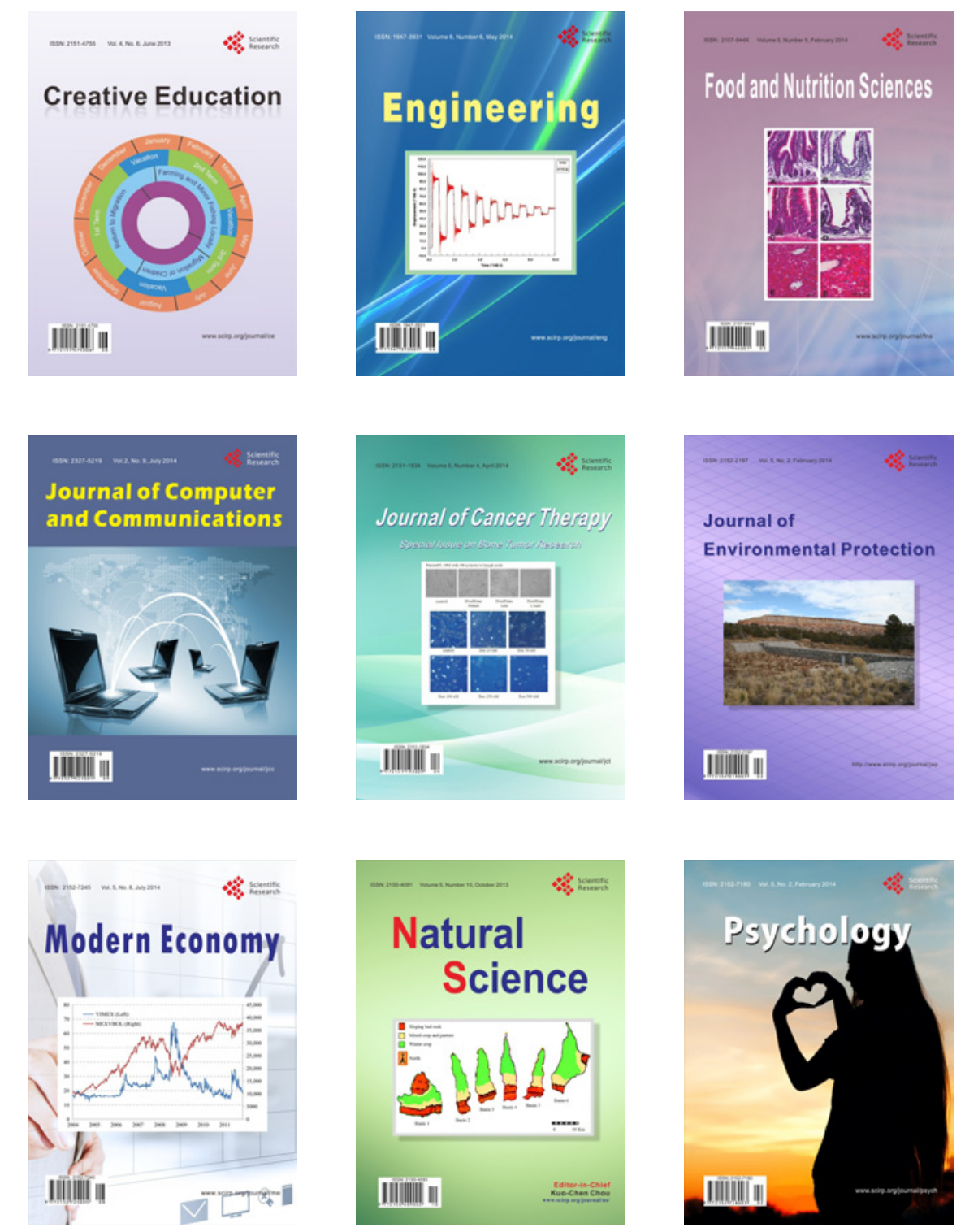